\title{
Chlamydial, gonococcal, and herpes virus infections in neonates
}

\author{
G. W. CSONKA \\ M.D., F.R.C.P., F.R.C.P.E. \\ E. D. COUFALIK*
M.D., Sc.D., D.C.H. \\ Department of Venereology, Central Middlesex Hospital, London NWIO and \\ *Clinical Research Centre, Northwick Park Hospital, Harrow
}

\begin{abstract}
Summary
The incidence, type of lesions, portal of entry and treatment of chlamydial, gonococcal, and herpetic infections of neonates are briefly discussed. Herpes neonatorum is potentially the most serious of these conditions and major efforts in its prophylaxis are called for.
\end{abstract}

\section{Chlamydial infections in neonates}

Chlamydiae are now recognized as one of the causes of non-specific urethritis in men, cervicitis in women, and 'sticky eyes' in infants born to these women. The dependence of conjunctivitis on a genito-urinary source and its occurrence within the first 3 weeks of life was first reported by the Viennese ophthalmologist Lindner in 1908 (reviewed by Thygeson, 1971) and has been confirmed and greatly elaborated in the past 12 years by several investigators including Dunlop, Jones and Al-Hussaini (1964) and Jones, Al-Hussaini and Dunlop (1964).

According to Dr Hobson, the incidence of sticky eyes due to Chlamydia in his series in Liverpool is around $30 \%$, which is one of the highest reported. Clearly not all sticky eyes are due to Chlamydia.

There is some uncertainty about the ultimate fate of 'Chlamydia-associated' sticky eyes. Jones (1964) has found that some infants develop trachomatous changes later, and experimental inoculation of Chlamydia from the sticky eyes of neonates into the conjunctival sac of adult volunteers resulted in clinical trachoma. However, experience on the whole suggests that a trachomatous change in neonatal conjunctivitis is a rare event.

Neonatal chlamydial conjunctivitis does not respond to routine neomycin eye drops but can be cleared with eye drops containing tetracycline or sulphonamides.

\section{Gonorrhoea in neonates}

The points which will be briefly discussed are incidence, types of lesion, portal of entry and treatment.

Correspondence: Dr G. W. Csonka, Consultant Venereologist, Central Middlesex Hospital, Park Royal, London NW10.
Although gonorrhoea has been increasing year by $\vec{\omega}$ year until recently, the incidence of gonococcal infections recorded in neonates is surprisingly low $\overrightarrow{0}$ e.g. in England and Wales the latest published figure 3 . for gonococcal ophthalmia was only thirty-fourc (Annual Report of the DHSS for 1974), yet gono-os coccal ophthalmia is the most common lesion in $N_{\perp}$ infants born to mothers with gonococcal cervicitis. if Other gonococcal infections of the newborn mayN involve the genitalia producing urethritis, vulvitis, 으 vaginitis and are very rare, as are meningitis, $\vec{O}$ pharyngitis and gonococcal arthritis. Nevertheless? they do occur and one should be aware of their $\stackrel{?}{0}$ existence. Recently the authors observed an infant $\Phi$ with acute arthritis of a wrist first noticed on the $\vec{T}$ seventh day of life. Gonococci were isolated frow the joint and the gonorrhoea complement fixation. test (GCFT) was positive. The mother was found $\bar{E}$. have gonococcal cervicitis. The infant responded promptly to systemic penicillin. Any acute arthritis occurring within a few days of birth should be considered as being possibly due to the gonococcus. $\mathbb{Q}$

The mode of infection of an infant's eyes is by $\overrightarrow{\vec{O}}$ direct contact with the infected cervix during passage $\frac{3}{3}$ through the birth canal. In the rare cases of genital infection of the newborn, the infant's genital mucosa? becomes infected by the gonococcus, also by direct $\overline{0}$ contact and particularly where there has been a 3 . breech presentation (Forfar and Arneil, 1973). In systemic gonorrhoea, for example gonococcal arthritis, there is some uncertainty about the portal $ᄋ$ of entry of the organism. Most observers believe that $₹$ systemic infection follows entry through the mouth 음 during birth, however, the possibility of trans- $\rightarrow$ placental spread just before birth has not yet been excluded and might account for infants developing $N$ gonococcal arthritis very soon after birth (Gregory, Chisom and Meadows, 1972).

In the treatment of neonates with gonorrhoea, ్ㅗㅇ systemic penicillin is still very effective in doses of $\bar{\gamma}$ $50000 \mathrm{u}$. $/ \mathrm{kg} /$ day for 5 days, and there is practically 6 no danger of allergy to penicillin in the neonate. In $\$ ophthalmia, systemic penicillin is usually combined $\stackrel{\mathcal{P}}{+}$ with penicillin eye drops. One should perhaps warn $ᄁ 0$ against relying on chloramphenicol eye drops, as $\frac{\vec{D}}{\mathbb{D}}$ 
sometimes practised, as the drug only suppresses rather than eradicates the infection in most cases. It may be of interest to mention that in the past all the isolates from adults or neonates with systemic gonorrhoea have been found to be highly sensitive to penicillin. However, recent reports indicate that one should be aware of the emergence of penicillinresistant, penicillinase-producing strains (Leading Article, 1976). So far as prophylaxis is concerned, Crede's method of prophylaxis against neonatal ophthalmia has largely been abandoned. Further, there is no national policy to screen pregnant women for gonorrhoea as there is in the case of syphilis.

It would seem difficult to justify routine screening for gonorrhoea because of the uncertainty of excluding the infection in a woman on the strength of a single test, and also because of the low incidence of perinatal infection and the ease of curing it-at least at the present time. This situation and present ideas may change.

\section{Herpes simplex infection in neonates}

Genital infection due to herpes virus hominis in the adult is frequently seen in clinics dealing with sexually transmitted diseases and is in fact the most common cause of genital ulceration (Hutfield, 1970).

Clinically, the lesions may vary from the classical cluster of vesicles to those which are less typical in appearance-for example, single lesions, erosive balanitis and cervicitis or erythema alone. The authors believe, therefore, that the incidence of genital herpes is being underestimated. At the present time neonatal herpetic disease is found in 1 out of 75000 deliveries (Vaughan and McKay, 1975). Infants born to mothers with genital herpes in late pregnancy may develop herpes infection within the first 3 weeks of life, usually between the fifth and eleventh day. The lesions involve the skin, the eyes (as vesicular conjunctivitis), the mouth (as stomatitis), internal organs and especially the CNS, giving rise to meningoencephalitis. Herpetic ulceration on infants' buttocks and genitalia, particularly when followed by secondary infection, may be mis-diagnosed as ammonia nappy rash. The viral infection can often be demonstrated by the presence of antibodies of the IgM type in sera of CSF. The mortality rate of the disseminated form, especially when the CNS is affected, is very high and in some series has reached over $80 \%$ and the survivors have often had severe brain damage.

More work is required to understand the way in which neonates become infected by the herpes virus. Nahmias and colleagues believe that the herpes virus type 2 does not cross the placental barrier and that infection of the fetus occurs only perinatally (Nahmias, Alford and Korones, 1970; Nahmias et al., 1976). They advocate Caesarean section before membrane rupture as a prophylactic measure in cases of high risk. In their series, the risk of herpetic infection of the infants of mothers with genital herpes varied with the type of delivery, thus with vaginal delivery $54 \%$ of the infants were infected, with Caesarian section more than $4 \mathrm{hr}$ after membrane rupture it was $94 \%$ and with Caesarian section before or within $4 \mathrm{hr}$ of membrane rupture it was only $7 \%$. However, there are other relevant factors to be considered-there is some evidence that type 1 herpes virus may cross the placental barrier (Horman et al., 1973; Hanshaw, 1973), and there is evidence that the oral herpes virus type 1 infection of the cervix and vagina is increasing, presumably owing to an increase in orogenital sexual practices. Another point which should be taken into account before deciding on the mode of delivery is whether the maternal infection is primary or a recurrent one as the risk to the fetus is considerably less with recurrent attacks (Juel-Jensen, 1976).

Specific treatment of established herpetic disease in the newborn with the antiviral drugs such as 5iodo-deoxy-uridine and cystosine arabinoside (AraC) is unsatisfactory, and indeed these drugs may make matters worse; however, most recent evidence suggests that adenosine arabinoside (Ara-A) is less toxic and may be useful in treating neonatal encephalitis (Bauer, 1976). Experiments in rodents indicate that interferon inducers such as Poly-IC* given in high concentrations even as a single dose are of some value; it remains to be seen whether this form of treatment will prove useful in man (Catalano, 1969).

One can conclude that of the three infections which have been briefly discussed, genital herpes in late pregnancy is potentially the most serious one for the infant.

\section{References}

AnNual Report of the Chief Medical Officer for 1974 (1976) British Journal of Venereal Diseases, 52, 351.

BAUER, D.J. (1976) Chemotherapy of virus infections. In: Advanced Medicine, p. 466. Pitman Medical Books, London.

Catalano, L. (1969) Poly-IC. Journal of Pediatrics, 75, 1202.

DunloP, E.M.C., Jones, B.R. \& Al-Hussaini, M.K. (1964) Genital infection in association with TRIC virus infection of the eye. British Journal of Venereal Diseases, 40, 33.

Forfar, J.O. \& ARNEIL, G.C. (1973) Textbook of Paediatrics, p. 1401. Churchill Livingstone, Edinburgh and London.

Gregory, J.B., Chisom, J.L. \& Meadows, A.T. (1972) Gonococcal arthritis in an infant. British Journal of Venereal Diseases, 48, 306.

Hanshaw, J.B. (1973) Herpesvirus hominis infection in the fetus and newborn. American Journal of Diseases of Children, 126, 546.

Horman, A.L., Gershon, A.A., Blacketr, P.R. \& Nahmias, A.J. (1973) Intrauterine infection with herpes simplex virus. Journal of the American Medical Association, 225, 129.

* Poly I: poly C (polyinosinic polycytidylic acid complex). 
HutField, D.C. (1970) Genital herpes. British Journal of Hospital Medicine, 3, 881.

JONES, B.R. (1964) Genital trachoma. Revue internationale du trachome, 41, 425.

Jones, B.R., Al-Hussaini, M.K. \& Dunlop, E.M.C. (1964) Genital infection in association with TRIC virus infection of the eye. British Journal of Venereal Diseases, 40, 19.

Juel-Jensen, B.E. (1976) Antiviral compounds with special reference to genital herpes. In: Sexually Transmitted Diseases, p. 177, Academic Press, London, New York, San Francisco.

Leading Article (1976) Penicillinase-producing gonococci. Lancet, ii, 725.
Nahmias, A.J., Alford, C.A. \& Korones, S.M. (1970 Infection of the infant with herpesvirus hominis. Advance $D$ in Pediatrics, 17, 185.

Nahmias, A.J., Josey, W.E., Naib, Z.M. \& Visintime, A.M: (1976) Genital herpetic infection-the old and the new. In Sexually Transmitted Diseases, p. 148. Academic Press, London, New York, San Francisco.

THYGESON, P. (1971) Historical review of oculogenita disease. American Journal of Ophthalmology, 71, 975.

Vaughan, V.C. \& MCKaY, R.J. (1975) Nelson's Textbook of, Pediatrics, p. 664. Saunders, Philadelphia. 